\title{
COORDINATION OF COMPETENCIES DEVELOPMENT WITHIN NETWORKS OF SMES
}

\author{
Xavier Boucher, Emilie Lebureau \\ Ecole des Mines de Saint-Étienne - Centre G2I \\ 158 cours Fauriel,42023 Saint Etienne Cedex 2, France \\ \{boucher,lebureau\}@emse.fr
}

\begin{abstract}
That paper tackles the issue of competence increase in networks of firms, taking advantage of collaborative relationships. By hypothesis we limit our approach to competence increase for individual firms within a network, and we don't cover the increase of collective competence of the network itself. We develop a framework of decision support system, which objective is to compare alternative plans of actions for the collaborative development of competencies. We use a multi-criteria decisional method, and we formalize the decision process based on five criteria including the evaluation of value creation, cost generation and equity between partners. We apply the approach to an industrial case study of SMEs, in the field of software development.
\end{abstract}

\section{INTRODUCTION}

At the beginning of the 90's (Prahalad \& Hamel, 1990) defined core competences as the "collective learning in the organization, especially how to coordinate diverse production skills and integrate multiple streams of technologies". Such definition seems to be really pertinent in many cases of emergence of networks of firms, where several firms often try and cooperate in order to make operational a new "collective corpus of competences". Indeed a network of firms provides an intermediary way of coordination between the coordination of the integrated firm and the coordination by the market. It gives the advantage of a real flexibility in the composition of the network, due to potential changes in the partners. Taking advantage of the cooperation, it provides higher innovation capabilities as well as opportunities of savings on transactions costs, which can even be applied to competencies transfers (Tuma, 1998) .

(Doz \& Hamel, 1998) point out that « companies often turn to alliances to win the learning race. These are often faster and more effective than alternative approaches to learning...Alliances are often the best way for companies to quickly acquire and deploy new skills ". The approaches of "Resource-based view " initiated by B.Wernerfelt (1984) and " Competence-based view » by R.Sanchez \& al. (1996) are the more coherent for this exchange vision of inter-organizational exchanges and also for competencies development. The Winner /Winner relationship makes possible to increase individual performances for each partner, induced by the 
collaborative growth. In that perspective, firms should consider cooperation as a central element of their competencies development processes.

Thus, (Peillon, 2001) synthesizes the main characteristics of those networks aiming at competence development :

- The partnerships between firms are durable and motivated by a shared strategy on competence development, even if each partner keeps its own goals.

- The network consists in relations characterized by interdependencies and by shared investments, for which the notion of equity between partners is a major issue for a good coordination of collaborative actions.

Through recent research, several contributions have underlined the necessity of formal decisional methods applied to competence management (Manthou \& al, 2004), (Fischer \& al, 2004), (Szegheo \& Petersen, 2000). In that perspective, we propose below a regulation mechanism for the competencies exchanges within networks of firms to search optimum gains on learning and costs for the partners as well as equity in the share of those gains within the network. Indeed, even if cooperation provides an interesting reduction of costs and risks linked to interorganizational learning processes, we must not forget the necessity of balancing mechanisms in order to ensure equity between the partners on gains and losses. The notion of equity has been largely applied in the economic transactions, but we propose to formalize it for an application to the evaluation of inter-organizational learning processes.

However, by hypothesis, we limit the approach to the collaborative development of competencies for individual firms within a network. We don't deal with the concept of collective competence of the network itself, which would require models not available yet.

The paper is divided into 5 sections. Section 2 introduces the industrial case study. We deal with the issue of competence identification and evaluation in section 3. Then, section 4 introduces the notion of scenario for collaborative competence development, and formalizes the decisional process to compare alternative scenarios. Section 5 provides conclusions and perspectives.

\section{CASE STUDY}

The case study presented here stems from a collaboration with a network of firms named ARTIC. The origin of the network was the necessity of collaboration between very small to small firms in order to ensure on the long run their position on the competitive market. The association ARTIC gathers about twenty firms from similar sectors : the SMEs considered in that paper are all working in design and sell of software products. We will focus the formal study on the case of 3 of those companies For confidentiality, the concrete information we use is juggled.

In order to manage the creation of tighter cooperation within the network, ARTIC has launched a systematic identification of competencies' maps of the firms and an evaluation of their competencies levels. The identification and evaluation of competencies in use was based on an internal audit procedure clearly defined in (Grecopme, 2003). In order to make possible a systematic comparison between distinct firms' profiles of competencies, the audit was based on competencies reference grids linked to their specific activity field as we underlined in section 3.1. 


\section{COMPETENCE QUALIFICATION}

That section aims at explaining the evaluation of firms' competencies used as a basis to analyze potential competence-based cooperation. The qualification of competencies we propose provides an evaluation of the needs of competence development for each firm of the network.

\subsection{Competence model and competence sets}

Our research focuses on a systemic view on competence, using the s-a-r-C model (Boucher \& Burlat, 2003) to describe firms competencies without restricting the notion of competence to actors' skills. On the contrary, we consider that the competence of a firm depends on three main aspects : the methods deployed in the firm (modellized with the concept of professional situations), the skills of employees (modellized with the concept of actors) and the technological context (modellized with the concept of material resource). Thus, the s-a-r-C competence model formalizes that the competence emerges from the interaction between these 3 major components: "the professional situations, the actors, and the material resources".

Each firm of the network is to be described by a set of competencies. The identification of sets of competencies requires competencies dictionaries or competencies reference grids. In France, the national reference grid ROME (Répertoire Opérationnel des Métiers et de l'Emploi) offers the advantages to provide a national standard and to be based on aggregated descriptions of competencies. However it keeps very general. For the industrial case study we needed to develop competence grids more detailed and more specific to the activity field of the firms (Grecopme, 2003). Such reference grids make easier a systematic identification of competencies as well as the systematic decision aid we propose.

Further more, referring to a formalism developed in (Boucher \& Burlat, 2003), the sets of competencies identified with the audit are formalized using the fuzzy subsets theory (Zadeh, 1965). Indeed, we are considering that a firm $\mathrm{E}$ can be described by an h-rank finite set of competencies $C(E)=\left\{C_{1}, C_{2}, \ldots C_{h}\right\}$. Let $C_{j}$ be an element of $\mathrm{C}(\mathrm{E})$. We note $\widetilde{X}$ the fuzzy subset defined by $\tilde{X}=\left\{\mathrm{C}_{1} \mid \mu_{\mathrm{X}}\left(\mathrm{C}_{1}\right)\right.$, $\left.\mathrm{C}_{2}\left|\mu_{\mathrm{X}}\left(\mathrm{C}_{2}\right), \ldots, \mathrm{C}_{\mathrm{h}}\right| \mu_{\mathrm{X}}\left(\mathrm{C}_{\mathrm{h}}\right)\right\}$ where $\mu_{\mathrm{X}}\left(\mathrm{C}_{\mathrm{i}}\right)$ is the characteristic membership function of $\mathrm{C}_{\mathrm{i}}$ in $\tilde{X}, \mu_{\mathrm{X}}\left(\mathrm{C}_{\mathrm{i}}\right)$ takes its values in $[0,1]$. The characteristic function will be used to assess the levels of competencies of a given firm.

\subsection{Qualification of competencies}

Our goal is also to provide an evaluation of firms' competencies levels. Competencies can be characterized by different measures of "competencies levels". For a given application in an organization, the evaluation of the three components \{s-a-r\} provides a first qualification of competencies that we call the "theoretical level of competence". To calculate this theoretical level of competence we have defined in (Boucher \& Burlat, 2003) indicators on situations, actors, and resources. We consider :

$S=\{S 1, S 2, \ldots S p\}$ a finite p-rank subset of situations, characterized with an indicator named firm "expertise level" on the professional situation. That indicator 
can be assessed referring to several factors like the degree of rationalization on the professional situation and the frequency on such situation.

$A=\{A 1, A 2, \ldots A q\}$ a finite q-rank subset of actors, characterized with an indicator named "actor suitableness" to the situation, relating to the availability of the actors and to the cognitive abilities required.

$\mathrm{Q}=\{\mathrm{Q} 1, \mathrm{Q} 2, \ldots \mathrm{Qr}\}$ a finite r-rank subset of resources, characterized by an indicator named "service level", relating to the availability of the technical resources and the technological capabilities required for the situation.

Those three indicators provide us with control parameters, later used for the competency development actions plan. We defined in (Boucher \& Burlat, 2003) and in (Grecopme, 2003) various ways to aggregate those indicators in the final theoretical level of competence, referring to the fuzzy subsets theory we are using. Table 1 presents the notations used for the three indicators as well as for the Theoretical competence level $\mu_{\tilde{N}(E)}\left(C_{i}\right)$ resulting from the aggregation.

\subsection{Targets on competence development}

We consider that the competence development strategy for each firm directly depend on the top management of the firm. The managers are asked to make explicit that strategy, by providing a set of target competencies levels to be reached.

The target level of the competency $C_{i}$ for the firm $E$ within the network provides the value of the characteristic membership function $\mu_{\widetilde{O}(E)}\left(C_{i}\right)$ (Table 1). For the entire network, we formalize various sets of targets, each set representing a competence development strategy for one of the partners.

Table 1 - Basic mathematical characteristics

\begin{tabular}{|l|l|}
\hline Data & Explanation \\
\hline$\mu_{\tilde{Q}(E)}(C)$ & "Resource service" level in a competence $C_{\mathrm{i}}$ for a firm $\mathrm{E}$. \\
\hline$\mu_{\tilde{A}(E)}\left(C_{i}\right)$ & "Actors suitableness" level in a competence $\mathrm{C}_{\mathrm{i}}$ by a firm $\mathrm{E}$. \\
\hline$\mu_{\tilde{S}(E)}\left(C_{i}\right)$ & "Expertise level" of the actors in a competence $\mathrm{C}_{\mathrm{i}}$ by a firm $\mathrm{E}$. \\
\hline$\mu_{\tilde{N}(E)}\left(C_{i}\right)$ & Theoretical level of competence : $\mu_{\tilde{N}(E)}\left(C_{i}\right)=M i n\left(\mu_{\tilde{S}(E)}\left(C_{i}\right), \mu_{\tilde{A}(E)}\left(C_{i}\right), \mu_{\tilde{Q}(E)}\left(C_{i}\right)\right)$ \\
\hline$\mu_{\tilde{O}(E)}\left(C_{i}\right)$ & Target on competence level by a firm $\mathrm{E}$ of the network, on a competence $\mathrm{C}_{\mathrm{i}}$ \\
\hline
\end{tabular}

\subsection{Competence developments needs}

Within the network, each enterprise $\mathrm{E}$ is characterized by a set of competencies $\mathrm{C}(\mathrm{E})$ $=\left\{C_{1}, C_{2}, \ldots C_{n}\right\}$, with $i$ taking values from 1 to $n$. Using a comparison between the target levels and the theoretical levels of competence we can calculate a pertinence indicator $\rho_{1}$, defined in (Boucher and Burlat, 2003) which measures for each enterprise the overall gap between the competencies available and the targets.

$$
\rho=1-\frac{1}{n} \sum_{i=1}^{n}\left|\mu_{\widetilde{N}(E)}\left(C_{i}\right)-\mu_{\widetilde{\alpha}(E)}(C i)\right|
$$

This indicator corresponds to a notion of "pertinence", i.e. the appropriateness of the means implemented with respect to the targets. In the case of ARTIC, the firms have identified 10 basic competencies (both technical and managerial competencies) 
to be potentially developed in cooperation within the network. Table 2 indicates the gap between target and competence for the three firms considered (with $\mu_{\tilde{O}(\mathrm{E})}(C)$ the target level for each competence and $\mu_{\widetilde{N}(E)}\left(C_{i}\right)$ the theoretical competence level).

Table 2 - Initial data for the case study "ARTIC"

\begin{tabular}{|c|c|c|c|c|c|c|c|c|c|c|}
\hline & & & terprise 1 & & & iterprise 2 & & & nterprise 3 & \\
\hline $\begin{array}{l}\text { Conpet } \\
\text { encies }\end{array}$ & Name: "To be able to... & $\mu \widetilde{O}(t)(C$ & $\mu_{\tilde{N}(E)}(C)$ & & $\mu_{\tilde{O}\{(\mathrm{~B})}\left(C_{i}\right)$ & $\mu_{\tilde{N}(E)}\left(C_{i}\right)$ & & $\mu \tilde{O}(E)_{(E)}(C)$ & $\mu_{\widetilde{N}(E)}(C)$ & \\
\hline${ }_{1}^{\mathrm{C}}$ & $\begin{array}{l}\text { Conceive business } \\
\text { software }\end{array}$ & 1 & 0,5 & 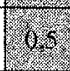 & 0,75 & 0 & & 0,5 & 0,35 & \\
\hline $\mathrm{C} 2$ & $\begin{array}{l}\text { Achieve } \\
\text { programming }\end{array}$ & 0,5 & 0,5 & & 0,5 & 0,5 & & 1 & 0,72 & \\
\hline $\mathrm{C} 3$ & $\begin{array}{l}\text { Master software } \\
\text { adaptability and } \\
\text { evolution }\end{array}$ & 1 & 0,63 & & 0,5 & 0 & & 0,75 & 0,4 & \\
\hline $\mathrm{C} 4$ & Control quality & 0,75 & 0,5 & & 0,75 & 0 & 107 & 0,5 & 0,38 & 0 \\
\hline $\mathrm{C} 5$ & $\begin{array}{l}\text { Bring under control } \\
\text { quality-costs-lead } \\
\text { times }\end{array}$ & 1 & 0,5 & & 0,75 & 0 & & 0,5 & 0,5 & \\
\hline C6 & $\begin{array}{l}\text { Keep in line with } \\
\text { quality standards }\end{array}$ & 0,25 & 0 & & 0,5 & 0 & 16 & 0,5 & 0 & \\
\hline C7 & $\begin{array}{l}\text { Stage campaigns for } \\
\text { quality continuous } \\
\text { improvement }\end{array}$ & 0,5 & 0 & & 0,5 & 0 & & 0,5 & 0 & \\
\hline $\mathrm{C} 8$ & Achieve marketing & 1 & 0 & 210 & 0,25 & 0 & 10,25 & 0,5 & 0,5 & 10 \\
\hline C9 & $\begin{array}{l}\text { Manage customer } \\
\text { relationship }\end{array}$ & 1 & 0 & & 0,75 & 0,38 & 0,37 & 0,75 & 0 & \\
\hline $\mathrm{ClO}$ & Manage sales & 1 & 0,25 & 1075 & 1 & $\overline{0,64}$ & 0,6 & 0,75 & 0 & (3) \\
\hline
\end{tabular}

Such data provide us with the identification of the competence development needs of each firm. Then we can define actions of competence development aiming at reducing that pertinence gap, and of course we will take advantage of the network to implement cooperative actions of competence exchanges. Section 4.3 underlines the procedure used to identify potential actions for a specific network.

We deal with elementary actions, each of them only applied to one of the three components of the competence "situation", "actors" or "resources". A given action of competence development $w_{j}$ has an impact on the level $\mu_{\tilde{Q}(E)}(C)$ or $\mu_{\tilde{A}(E)}\left(C_{i}\right)$ or $\mu_{\widetilde{S}(E)}\left(C_{i}\right)$. So the theoretical competence level shifts from a $\mu_{\widetilde{N}(E)}\left(C_{i}\right)$ to a new value $\mu_{\tilde{N}^{\prime}(E)}\left(C_{i}\right)$. The action of competence development creates an increment $\Delta\left(E_{i}, w_{j}\right)$ of the theoretical competence level for a enterprise $E_{i}$, with $\left(\mu_{\widetilde{N}^{(}(E)}\left(C_{i}\right) \geq \mu_{\widetilde{N}(E)}\left(C_{i}\right)\right)$ because the $w_{j}$ are improvement actions.

\section{COOPERATIVE SCENARII OF COMPETENCE INCREASE}

\subsection{Hypothesis on competence development}

The decisional process we propose below refers to the following restrictions :

- We only deal with the development competencies of the firms considered individually;

- Therefore, the actions of competence development are based on competence 
similarities. They don't cover potential complementarities of competencies which could lead to a collective competence.

- The decisional process will support the equitable identification of collaborative actions of competence development. Those actions could also be completed in each firm by complementary investments if necessary.

The goal of the decisional process presented below is to select competencies development actions in order to improve the pertinence, i.e. in order to reduce the gap between the targets and the available levels of competence. In this perspective, we formalize various alternatives of cooperation on competencies, and we define a decision support procedure to guide the collaborative building of plan of actions. The alternative plans of action to be compared are called "scenarios". The selection of a scenario within a network will respect the two following principles:

(1) Maximization of the increase of competencies for each enterprise (with regards to their targeted goal for competence development) by a conceptual use of actions in cooperative mode.

(2) Equitable balancing between the increases of competencies of each partner.

Indeed we underlined before that even if the cooperation provides an interesting value-added to inter-organizational learning processes, we can not forget the necessity of equity between the partners to share the gains and losses.

\subsection{Decisional criteria}

To fit both principles, the classification of scenarios for collaborative development of competencies can be processed in a systematical way referring to several criteria including equity measures. In that perspective, we define in that section five decisional criteria to make possible the comparison of the alternative scenarios. Each scenario (i) includes a set of competence development actions $\left(\mathrm{w}_{\mathrm{j}}\right.$ ), (ii) can have impact on several competencies, and (iii) can have impact on several partners. Thus, to proceed to scenarios comparison, we need global indicators concerning all the partners and all the actions in each scenario.

Furthermore, we decided to distinguish between equity on value creation and equity on costs because both constitutes two different regulation variables : a more aggregated vision would reduce the precision of the decision to be taken.

\section{- Value induced by a plan of actions}

First, for each action, we need to evaluate the local improvement on the competency components. As underlined in section 3.4, a given action will change the theoretical competence level from $\mu_{\widetilde{N}_{(E)}(C)}$ to the new value $\mu_{\widetilde{N}^{\prime}(E)}\left(C_{i}\right)$. Thus, for a set of actions W(R) selected by the network of SMEs, we have a global increment of the theoretical competence level written:

$$
\Delta(E, W(R))=\sum_{i=1}^{n}\left(\mu_{\tilde{N}^{\prime}(E)}\left(C_{i}\right)-\mu_{\tilde{N}_{(E)}}\left(C_{i}\right)\right)
$$

This increment $\Delta(E, W(R))$ measures the increase of competence due to the scenario $\mathrm{W}(\mathrm{R})$ for a specific partner $\mathrm{E}$. Considering $\mathrm{k}$ firms within a network, the indicator $\mathrm{I}_{1}$ measures the overall competence increase induced by $\mathrm{W}(\mathrm{R})$ on all the partners: 


$$
I_{1}(\mathrm{~W}(\mathrm{R}))=\sum_{j=1}^{k} \Delta\left(\mathrm{E}_{j}, \mathrm{~W}(\mathrm{R})\right)
$$

\section{- Equity on competence increase}

The equity on competence increase is an equity between the value transmitted by each partner to the network and the value he acquires on its side. In fact, we measure the homogeneity of the ratios between the transmitted value and the acquired value (one ratio for each partner). As an hypothesis, we consider that a "transfer of value" is an organizational learning action, where a firm $E$ induces a competence increase for its partners in the network, without any competence increase for $\mathrm{E}$. We call "acquisition of value" the opposite mechanism.

Equity would be that the global competence increase would be fairly shared between all the partners. For every action $w_{j}$ and for every enterprise $E_{i}$, we use the variable $v\left(E_{i}, w_{j}\right)$ to indicate if the action $w_{j}$ is a transfer of value (in that case $v\left(E_{i}, w_{j}\right)=1$ ) or an acquisition of value (in that case $\mathrm{v}\left(\mathrm{E}_{\mathrm{i}}, \mathrm{w}_{\mathrm{j}}\right)=0$ ) for Ei. Considering $\mathrm{m}$ actions and $\mathrm{k}$ enterprises, the ratio $R$ between the transmitted value and the acquired value for the firm $E_{i}$ is given by:

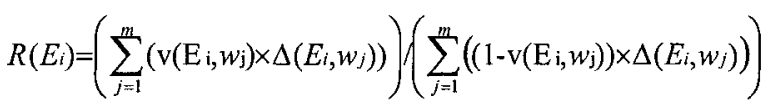

For a partner when that ratio tends to 1 , there is a good balance between the competence he provides to its partners and the competence he can get from them. But we need an overall indicator, to compare two scenarios taking into account all the partners. Within the network, the equity indicator $I_{2}$ gives an estimation of the dispersion on the ratios $R\left(E_{i}\right)$ by a classical variance measure:

$$
I_{2}(\mathrm{~W}(\mathrm{R}))=1 /(k-1) \sum_{i=1}^{k}\left(R\left(E_{i}\right)-M_{R}\right)^{2} \text { with } \mathrm{M}_{\mathrm{R}} \text { the mean of the ratios. }
$$

\section{- Overall costs induced by a scenario}

This function is the sum of the costs stemming from the implementation of the actions of competencies development, supported by the $\mathrm{k}$ enterprises of the network.

$$
I_{3}=\sum_{i=1}^{k} \operatorname{costs}\left(E_{i}\right)
$$

The different costs are determined thanks to a system of reference which specify the calculi parameters to provide for each action.

\section{- Equity on costs}

We deal here with the equity on the costs stemming from the competence development actions. This equity is a measure of costs dispersion between the partners, with regards to the average cost for all of them. This indicator of equity 14 is calculated from the standard deviation of each partner $E_{i}$ costs to the average cost: 


$$
I_{4}=1 / k \times \sqrt{\sum_{1=1}^{k}\left(\cos t s\left(E_{i}\right)-M c\right)^{2}} \text { with } M c=I_{3} / k
$$

- Feasibility of the scenarios Each action of competence development can be characterized by its feasibility. The feasibilities are determined thanks to a system of reference which specify the calculi parameters to provide for each action. Then we evaluate the global feasibility of a scenario, by the average feasibility considering every action included in the scenario.

$$
I_{s}=\sum_{j=1}^{k} \frac{\text { feasibility }(w j)}{k}
$$

\subsection{AHP method}

The comparison of potential scenarios (i.e. sets of actions) uses the AHP (Analytic Hierarchical Process) developed by T.L Saaty. The decision-makers keep the possibility to provide different weights to the five previous indicators. This method presents the advantages to model the articulation between the individual objectives of each partner and the collective ones of the network, to give a clear visualization in the decision-makers preferences, and to easily generate various ranking of scenarios, according to the weights given to the five indicators.

\subsection{Application}

As we underlined before, the concrete application of the approach starts with an internal audit of the firms which provides us with the necessary data on sets of competencies, level of competencies et targets on competence development. The decisional process starts with a systematic analysis of the gap $\mathrm{e}_{1}$ between the targets and the actual theoretical competence levels (table 2).

A second phase of the decisional process consists in the systematic identification of potential actions on the situations, actors, and resources' of each firm, to try and reduce those gaps. The process we use for a systematic identification of potential actions has been described in (Boucher \& Lebureau, 2004). We use a generic typology of actions for the development of competencies and the concrete evaluations on situation, actors and resources for each competence to generate an exhaustive set of actions aiming at fulfilling the needs of the partners. Then, the actions set is also filtered using strategic, logical, or operational constraints concerning competence development to eliminate inconsistencies. Concerning the case study, that process result in a dozen of possible actions shown in table 3 .

The resulting set of actions gathers all the possibilities of cooperative competence development. However depending on technical or economical constraints, all the actions can not always be implemented together. Therefore, the third stage of the decisional process is the generation of consistent scenarios, with regards to such constraints. Those scenarios are subsets the initial set of potential actions. In this example, we consider that a budget constraint induces the selection of only 3 cooperative actions among the 12 possible identified. Thus in this case, there are 220 possible scenarios consisting of 3 actions $\left(\mathrm{C}_{3}{ }^{12}\right)$ that we have to 
compare in order to establish the most relevant in the cooperation objectives. The reader must remember that beyond selected cooperative actions, each company will supplement its action-plan with autonomous actions. Of course a change in this budget constraint would only modify the combinatory without modifying the proposed method.

Table 3 - Potential actions ${ }^{1}$ of competencies development for ARTIC case study.

\begin{tabular}{|l|l|}
\hline Actions & Actions definition \\
\hline $\mathrm{w}_{1 \mathrm{c}}\left[\mathrm{A} ; \mathrm{C} 4 ; \mathrm{E}_{\mathrm{s}} 3 ; \mathrm{E}_{\mathrm{b}} 1 / \mathrm{E}_{\mathrm{b}} 2\right]$ & Inter-enterprise competencies transmission for individual actors \\
\hline $\mathrm{w}_{2 \mathrm{c}}\left[\mathrm{A} ; \mathrm{C} 8 ; \mathrm{E}_{\mathrm{s}} 3 ; \mathrm{E}_{\mathrm{b}} 1 / \mathrm{E}_{\mathrm{b}} 2\right]$ & Inter-enterprise competencies transmission for individual actors \\
\hline $\mathrm{W}_{3 \mathrm{c}}\left[\mathrm{S} ; \mathrm{C} 8 ; \mathrm{E}_{\mathrm{s}} 2 ; \mathrm{E}_{\mathrm{b}} 1\right]$ & Best practices diffusion \\
\hline $\mathrm{w}_{4 \mathrm{c}}\left[\mathrm{A} ; \mathrm{C} 1 ; \mathrm{E}_{\mathrm{s}} 1 ; \mathrm{E}_{\mathrm{b}} 2 / \mathrm{E}_{\mathrm{b}} 3\right]$ & Inter-enterprise competencies transmission for individual actors \\
\hline $\mathrm{W}_{5 \mathrm{c}}\left[\mathrm{A} ; \mathrm{C} 3 ; \mathrm{E}_{5} 3 ; \mathrm{E}_{\mathrm{b}} 2\right]$ & Inter-enterprise competencies transmission for individual actors \\
\hline $\mathrm{w}_{6 \mathrm{c}}\left[\mathrm{S} ; \mathrm{C} 4 ; \mathrm{E}_{\mathrm{s}} 1 ; \mathrm{E}_{\mathrm{b}} 2 / \mathrm{E}_{\mathrm{b}} 3\right]$ & Best practices diffusion \\
\hline $\mathrm{W}_{7 \mathrm{c}}\left[\mathrm{S} ; \mathrm{C} 9 ; \mathrm{E}_{\mathrm{s}} 1 ; \mathrm{E}_{\mathrm{b}} 2 / \mathrm{E}_{\mathrm{b}} 3\right]$ & Best practices diffusion \\
\hline $\mathrm{w}_{8 \mathrm{c}}\left[\mathrm{A} ; \mathrm{C} 9 / \mathrm{C} 10 ; \mathrm{E}_{\mathrm{s}} 2 ; \mathrm{E}_{\mathrm{b}} 1 / \mathrm{E}_{\mathrm{b}} 3\right]$ & Inter-enterprise competencies transmission for individual actors \\
\hline $\mathrm{w}_{1 \mathrm{~m}}[\mathrm{~S} ; \mathrm{C} 1 ; \mathrm{E} 1 \mathrm{UE} 2 \mathrm{UE} 3]$ & Common Investment on methods \\
\hline $\mathrm{w}_{2 \mathrm{~m}}[\mathrm{~S} ; \mathrm{C} 4 ; \mathrm{E} 1 \mathrm{UE} 2 \mathrm{UE} 3]$ & Common Investment on methods \\
\hline $\mathrm{w}_{3 \mathrm{~m}}[\mathrm{R} ; \mathrm{C} 4 ; \mathrm{E} 1 \mathrm{UE} 2 \mathrm{UE} 3]$ & Common Investment on one resource hold by the network \\
\hline $\mathrm{w}_{4 \mathrm{~m}}[\mathrm{~A} ; \mathrm{C} 9 / \mathrm{C} 10 ; \mathrm{E} 1 \mathrm{UE} 2 \mathrm{UE} 3]$ & Mutual formation of the individual actors \\
\hline
\end{tabular}

The last decisional phase consists in the selection of the most favourable scenario for competence development. For all the 220 scenarios, we calculate the five decisional criteria thanks to the formula (1) to (5), and we apply the analytic hierarchical process. If the decision-makers give the same weight to every criterion, we get the following results :

Table 4 - Some scores of the best scenarios after multi-criteria ranking.

\begin{tabular}{|l|c|c|l|l|l|c|}
\hline Scenarios & SCORE & $\mathrm{I}_{\mathbf{1}}(\mathbf{1})$ & \multicolumn{1}{|c|}{$\mathrm{I}_{2} \mathbf{( 2 )}$} & \multicolumn{1}{|c|}{$\mathrm{I}_{\mathbf{3}} \mathbf{( 3 )}$} & $\mathrm{I}_{4} \mathbf{( 4 )}$ & $\mathrm{I}_{\mathbf{5}} \mathbf{( 5 )}$ \\
\hline Scenario_59 & $75.79 \%$ & {$[1.5 / 2[$} & {$[0.5 / 1[$} & {$[15000 / 20000[$} & {$[0.25 / 0.5[$} & {$[0.08 / 0.12[$} \\
\hline Scenario_116 & $74.74 \%$ & {$[1 / 1.5[$} & {$[0.25 / 0.5[$} & {$[15000 / 20000[$} & {$[0 / 0.125[$} & {$[0.08 / 0.12[$} \\
\hline Scenario_90 & $74.74 \%$ & {$[2 / 2.5[$} & {$[0.25 / 0.5[$} & {$[20000 / 25000[$} & {$[0.125 / 0.25[$} & {$[0.04 / 0.08[$} \\
\hline Scenario_175 & $72.63 \%$ & {$[1.5 / 2[$} & {$[0 / 0.125]$} & {$[20000 / 25000[$} & {$[0 / 0.125[$} & {$[0.04 / 0.08[$} \\
\hline Scenario_58 & $72.63 \%$ & {$[1.5 / 2[$} & {$[0 / 0.125[$} & {$[20000 / 25000[$} & {$[0.125 / 0.25[$} & {$[0.04 / 0.08[$} \\
\hline Scenario_190 & $72.63 \%$ & {$[1.5 / 2[$} & {$[0.125 / 0.25[$} & {$[20000 / 25000[$} & {$[0 / 0.125[$} & {$[0.04 / 0.08[$} \\
\hline
\end{tabular}

It is between these 6 scenarios that we find the better balance in the competence gains, costs, feasibilities and equity, since they get the three best notes. The final decision of the scenario to implement is to be taken by the network's managers. Their decision could be oriented by a qualitative analyze of the better noted scenarios : the scenario 90 is better for the global competence gain, but it is the worth for the global costs, the scenario_59 et scenario_116 are comparable in term of global costs and feasibilities, and if we choose to favor equity on the competences gains and costs, we would prefer the scenario_175.

The analysis of scenarios also shows the influence of interactions between competencies. For instance the actions $\mathrm{w}_{8 \mathrm{c}}\left[\mathrm{A} ; \mathrm{C} 9 / \mathrm{C} 10 ; \mathrm{E}_{\mathrm{s}} 2 ; \mathrm{E}_{\mathrm{b}} 1 / \mathrm{E}_{\mathrm{b}} 3\right]$ and $\mathrm{w}_{4 \mathrm{~m}}[\mathrm{~A}$; $\mathrm{C} 9 / \mathrm{C} 10$; E1UE2UE3] appear often in the best scenarios. It can be explained by the fact that they have impact on two competencies (the same actor supports C9 and

\footnotetext{
${ }^{1}$ In table 3, the notation wlc[A; C4; Es 3; Eb1/ Eb2] indicates that the action wlc has an impact on the actor $(\mathrm{A})$ for the competence $\mathrm{C} 4$, with the firms $\mathrm{E} 1$ et $\mathrm{E} 2$ as beneficiary-firm and $\mathrm{E} 3$ as root-firm.
} 
C10 competencies and shares knowledge on both competencies). The decision aid method presented here shows that interactions between competencies are a key element of our approach. Interactions between learning actions on actors, resources or situations within a same competence are taken into account in the calculation of the theoretical level of competence; and interactions between actions on distinct competencies (common actors or resources of distinct competencies) are taken into account in the calculation of actions impacts.

\section{CONCLUSION}

That paper is based on a formalization of the notion of firms' competencies, and it points out a collaborative decision process aiming at enhancing the competence development of partners within a network. On a conceptual point of view, the main value added consists in the decisional criteria which provide both an objective measure of the organizational learning a network of firms and a measure of equity concerning the transfer of competencies. Of course the approach is based on several restrictive hypothesis concerning the model of competencies, the way to make explicit a strategy of competencies, and the decisional process. Such hypothesis induce several perspectives which could enlarge the application field. The most important would be to take into account not only the development of similar competencies between firms, but also complementary competencies. On an applicative point of view that paper demonstrates the possibility to develop quantitative decision tools applied to the notion of competence management.

\section{REFERENCES}

1. Boucher X, Burlat P. "Vers l'intégration des compétences dans le pilotage des performance de l'entreprise". Journal Européen des Systèmes Automatisés 2003: 37(3). 363-390.

2. Boucher X, Lebureau E. "Practical Aspects of Knowledge Management". 5th International Conference PAKM 2004, Vienna, Austria, December 2-3, 2004. ISBN: 3-540-24088-8.

3. Doz Y, Hamel G. Alliance advantage: the art of creating value trough partnering. Boston : Harvard Business School Press, 1998.

4. Fischer M, Jahn H, Teich T. "Optimizing the selection of partners in production networks" Robotics and Computer-Integrated Manufacturing 2004 : 20. 593-601.

5. GRECOPME II, Burlat $P$ (coord.). Rapport final du projet de recherche GRECOPME II à la région Rhône-Alpes. Thématique prioritaire « Productique». September 2003.

6. Manthou V, Vlachopoulou M, Folinas D. "Virtual e-Chain (VeC) model for supply chain collaboration". International Journal of Production Economics 2004: 87. 241 - 250.

7. Peillon S. Le pilotage des coopération interentreprises : le cas des groupement de PME. Thèse de l'Ecole Nationale Supérieure des Mines de Saint Etienne. October 2001.

8. Prahalad, CK., Hamel G. "The core competence of corporation". Harvard Business Review MayJune 1990. 79-91.

9. Sanchez R, Heene A, Thomas H. Dynamics of Competence-based Competition. Elsevier,1996.

10. Szegheo O, Petersen SA. "Extended Enterprise Engineering - a model-based framework". Journal of concurrent engineering research and applications 2000: 8. 32-39.

11. Tuma, A. "Configuration and coordination of virtual production networks". International Journal of Production Economics 1998: 56-57. 641-648.

12. Wernerfelt B. "A Resource-Based View of the Firm". Strategic Management Journal 1984: 5, 171180.

13. Zadeh L. A., “ Fuzzy sets”. Information and Control 1965: 8. 338-353. 